\title{
ФОЛЬКЛОРИСТИКА
}

\section{Лиса как персонаж сказок о животных ойратов Синьцзяна}

\section{Баира Басанговна Горяева, Ю Лан ${ }^{2}$}

${ }^{1}$ Калмыцкий научный центр РАН (д. 8, ул. им. И. К. Илишкина, 358000 Элиста, Российская Федерация) кандидат филологических наук, старший научный сотрудник iD 0000-0001-9386-653X. E-mail: baira.goryaewa@yandex.ru

${ }^{2}$ Институт национальных литератур АОН КНР (Офис 1114, Жианней Дажие, 100732 Пекин, Китай) кандидат филологических наук, научный сотрудник iD 0000-0003-2444-6309. E-mail: yulan_003@163.com

(C) КалмНЦ РАН, 2020

(C) Горяева Б. Б., Ю Лан, 2020

Аннотация. Введение. Сказки о животных - древнейший жанр устного творчества. Генетически они восходят к мифам о животных, которые были порождены стремлением человека к познанию окружающего его мира. Мифы имели магическое значение для человека, который полагал себя состоящим в кровном родстве с животными и верил в то, что присущие ему черты характерны и для животных. Определяющими особенностями сказки о животных как жанра являются система персонажей, трюк как основа сюжета и диалог, создающий драматургию события. Сказки о животных являются органичной частью сказочного эпоса многих народов, в том числе и ойратов Синьцзяна КНР, в котором сказки о животных представлены в большом количестве. В фольклорных сборниках и в периодических изданиях на «ясном письме» опубликовано более ста образцов мифов и сказок, в которых главными персонажами выступают животные. Одним из основных персонажей таких сказок является лиса. Цель статьи - определить круг текстов сказок, в которых действующим персонажем выступает лиса, и раскрыть разные характеристики лисы как трикстера. Новизна работы заключается в том, что сказочный фольклор ойратов Синьцзяна, в том числе и сказки о животных, не введены в научный оборот и не были объектом исследования в российском монголоведении.

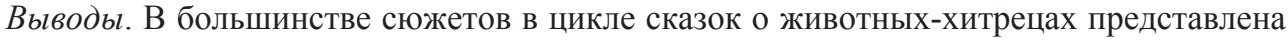
лиса. Следует отметить, что этому персонажу присущи как хитрость, так и глупость. Как видно из представленного материала, лиса далеко не всегда одерживает верх над другими персонажами, но достаточно часто становится их жертвой.

Ключевые слова: Ойраты Синьцзяна, сказки о животных, система персонажей, лиса, трикстер

Благодарность: Исследование выполнено при финансовой поддержке РФФИ и Академии общественных наук Китая в рамках научного проекта № 19-512-93002. 
Для цитирования: Горяева Б. Б., Ю Лан. Лиса как персонаж сказок о животных в фольклоре ойратов Синьцзяна // Монголоведение. 2020. Т. 12. № 2. С. 315-325. DOI: $10.22162 / 2500-1523-2020-2-315-325$

UDC 398.21(82-34)

DOI: $10.22162 / 2500-1523-2020-2-315-325$

\title{
Fox in Animal Tales of Xinjiang Oirats
}

\author{
Baira B. Goryaeva', Yu Lan ${ }^{2}$
}

${ }^{1}$ Kalmyk Scientific Center of the RAS (8, Ilishkin St., Elista 358000, Russian Federation) Cand. Sc. (Philology), Senior Research Associate iD 0000-0001-9386-653X. E-mail: baira.goryaewa@yandex.ru

${ }^{2}$ Institute of Ethnic Literature, Chinese Academy of Social Sciences (Room 1114, 5 Jiannei Dajie, Beijing 100732, People's Republic of China)

Ph.D. (Philology), Assistant Research Fellow

(iD) 0000-0003-2444-6309. E-mail: yulan_003@163.com

(C) KalmSC RAS, 2020

(C) Goryaeva B. B., Yu Lan, 2020

\begin{abstract}
Introduction. Animal tales are the oldest genre of oral art. Genetically, they go back to myths about animals developed through human aspiration to learn the outer world. Myths had a magical meaning for man who believed himself related by blood to animals, which inevitably resulted in attributing individual characteristics to personified animals. The defining features of animal tales as a genre are the system of characters, trick as a basis of the plot, and dialogue that creates the drama of events. Animal tales are an organic part of the magic epic of many peoples, including the Oirats of Xinjiang (China) where the former are presented in large numbers. Over a hundred texts of myths and fairy tales with animals as central characters have been published in Clear Script folklore collections and periodicals. One of the main characters to such fairy tales is fox. Goals. The article seeks to review texts of animal tales which reveal different characteristics of fox as a trickster, determine the range of fairy tale texts with fox as a main acting character. Fairy-tale folklore of Xinjiang Oirats of Xinjiang — including tales about animals - are thus newly introduced into Russian scientific discourse. Conclusions. Stories ending with triumphs of the sly fox constitute a majority of the tale cycle about sly animals. It should be noted that this character is equally characterized by cunning and stupidity. As is shown by the texts introduced, fox is far not always that victorious but rather may fall victim to other characters' deeds.
\end{abstract}

Keywords: Xinjiang Oirats, animal tales, system of characters, fox, trickster

Acknowledgements: The reported study was funded by RFBR and CASS, research project no. 19-512-93002.

For citation: Goryaeva B. B., Yu Lan. Fox in Animal Tales of Xinjiang Oirats. Mongolian Studies (Elista). 2020. Vol. 12. No. 2. C. 315-325. (In Russ.) DOI: 10.22162/2500-15232020-2-315-325

\section{Введение}

Сказки о животных являются органичной частью фольклора многих народов, в том числе и сказочного наследия ойратов Синьцзян-Уйгурского автономного района КНР, в котором они представлены в большом количестве. 
Огромный пласт текстов сказок ойратов Синьцзяна введен в научный оборот за два последних десятилетия фольклористами-монголоведами Китая - издано более пятидесяти сборников сказок [Damrindjab 2017]. При этом большая часть текстов издана на монгольской графике, и лишь часть - на «ясном письме», что представляет текстологическую проблему для исследователей. При переложении ойратского текста на монгольскую графику в силу различий между монгольским и ойратским языками наблюдается замена устойчивых ойратских выражений смысловыми монгольскими.

В фольклорных сборниках и в периодических изданиях на «ясном письме» опубликованы сказки, в том числе и о животных [Betege caүān boqširyo 1981; Šinǰiyang-giyin aman üliger 2006; Xān Tengger 1981-1998]. Сказки о животных отличаются от прочих сказочных сюжетов тем, что в их основе лежит трюк, а драматургия события создается с помощью диалога. Животные персонажи в сказках разумны и ведут себя подобно людям — их жизнь наполнена обычными житейскими хлопотами, ход которых нарушается неожиданным образом. В сложившейся ситуации персонажи действуют с помощью обмана в самых разных его формах, который является «основным композиционным стержнем» сказок о животных [Пропп 2000: 370]. Действие сказок о животных ойратов Синьцзяна также строится на основе обмана.

Одним из основных персонажей сказок о животных является лиса. Исследователи отмечают, что обычно в сказках о животных лиса всегда играет роль трикстера и действует обманом и хитростью [Басангова 2019: 13; Николаева 2010: 278]. По отношению к лисе у монгольских народов, в том числе у калмыков, бытуют разные представления. Нехорошей приметой у калмыков считалась встреча в пути с лисой, существовал запрет на ношение шапок из шкуры лисы. По мнению исследователей, лиса соотносима с нижним миром [Басангова 2019: 91]. По другим данным, кости ее черепа использовали в качестве амулета. Их крепили к вороту верхней одежды детей для отпугивания злых духов [Шараева 2011: 69]. Ойраты, проживающие в зоне Монгольского Алтая, Джунгарии, считают лису животным с «черным следом», т. е. приносящим несчастье [Содномпилова, Нанзатов 2016: 52].

У бурят лиса также связывается с нижним миром и важным персонажем высшей шаманской мифологии Эрлэн-ханом - властелином мира умерших, судьей мертвых. Помимо этого, считается, что лиса имеет отношение к солнечному божеству и небесному миру [Николаева 2010: 280]. В бурятских сказках и улигерах лиса среди прочих животных занимает довольно значимое место. В большинстве случаев лиса предстает в образе насмешницы, обманщицы и плутовки, благодаря ловким проделкам одурачивающей других животных и людей [Николаева 2010: 278].

\section{Общая характеристика материала исследования}

Нами рассмотрен 91 текст мифов и сказок о животных ойратов Синьцзяна, в 29 из них лиса выступает главным или действующим персонажем повествования. В подавляющем большинстве сюжетов лиса выступает в роли трикстера: она разными способами обманывает и дурачит людей и зверей. В. Я. Пропп, исследуя сказки о животных, отмечал, что на разных видах обмана основывается целый ряд сюжетов [Пропп 2000: 366]. 
Лиса обманывает разными способами: дает советы, уговаривает, льстит, вызывает сочувствие, сулит богатую пищу, угрожает. В сказках о животных каждый персонаж способен на обман, поскольку это своеобразная «форма выражения превосходства слабого над сильным» [Пропп 2000: 370]. Обычно к этому приему прибегают более слабые животные, которые не могут физически противостоять противнику. При этом обман осуществляется разными способами. Следует отметить, что по отношению к лисе чаще всего используются приемы, позволяющие усыпить ее бдительность: просьбы посчитать до восьми, перебросить жертву через голову и др. Поэтому лиса не всегда оказывается победителем, иногда она оказывается в роли неудачницы.

Как показывают исследованные нами синьцзянские сказки о животных, в них также присутствуют сюжеты о физически слабых существах, которые превосходят лису своей мудростью и смекалкой. Исходя из этого, мы разделили группу из 29 сказочных текстов о лисе на две части: те, что заканчиваются неудачей лисы, и те, где лиса торжествует победу. Если не учитывать варианты одних и тех же сюжетов, то получается, что сказки, в которых лиса терпит фиаско (16 текстов), составляют большинство по сравнению со сказками, в которых она берет верх над другими персонажами (13 текстов).

\section{Сюжеты сказок, где лиса проигрывает спор или оказывается обма- нутой}

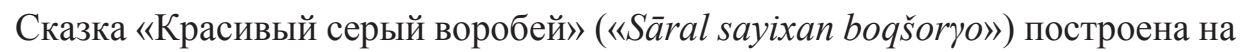
таком виде обмана, как запугивание. Лиса запугивает воробья и забирает яйца, которые тот высиживает. Мудрая перепелка учит воробья, как ответить лисе на ее угрозы. Когда лиса ловит перепелку, та с помощью хитрости освобождается из ее пасти [Хān Tengger 1981: 134-138; Šinǰiyang-giyin aman üliger 2006: 528-530]. В данном сюжете заметно буддийское влияние. Перед тем как быть съеденной, перепелка обращается к лисе со следующим советом:

- Если посчитаете до восьми, произнесете тарни (молитву) и потом съедите, то разве мясо мое не станет для вас аршаном (святым), а душа моя не возродится в стране Манджушри? (Нәәмн күртл то тоолад, номин тәрнәс кедүг умшад идхла, мини махн танд аршан болж, Манжуушрин орнд мини сүмсм төрх биший?) [Xān Tengger 1981: 138; Šinǰiyang-giyin aman üliger 2006: 530]. Когда лиса, разжав челюсти, произносит «восемь», перепелка вырывается из ее пасти.

Мотив счета как форма своеобразной уловки используется также в сказке «Соболь и лиса» («Bulyan bolon ünegen»). Лиса, прикинувшись странствующим монахом, выманивает из норы хорька, а затем выдру. Соболь, поддавшись льстивым уговорам лисы, оказывается пойманным, но освобождается, заставив лису посчитать до десяти [Betege саүān boqširyo 1981: 46-50; Šinǰiyanggiyin aman üliger 2006: 542-543]. Подобный сюжет известен и в калмыцком сказочном фольклоре.

Еще одним вариантом данного сюжета в ойратской сказочной традиции

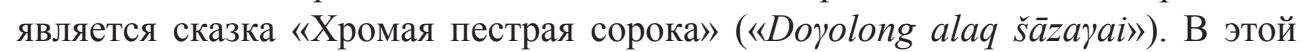
сказке охотник помогает сороке избавиться от угроз лисы [Xān Tengger 1988, № 3: 60-61; Šinǰiyang-giyin aman üliger 2006: 530]. 
Схожий сюжет встречается и в калмыцком сказочном фольклоре. В сказке «Баклан, лиса и суслик» («Бакльг, арат, зурмн һурвн») лиса пугает баклана и забирает яйца. Суслик подсказывает птице, как отвечать на угрозы лисы. Баклан сохраняет свое последнее яйцо, но забывает о наказе суслика, проговаривается и указывает лисе, в какую сторону он убежал. Лиса, поймав суслика, поддается на его уловку, начинает считать до десяти, суслик сбегает [Хальмг туульс 1961: 84-85].

В сказке «Почему у перепелки хвост короткий» («Bödüne-yin süül yayād oxotor boluqsan bui») сюжет построен на том, что лиса грозится съесть перепелку, если она: а) не рассмешит ее; б) не накормит; в) не напугает [Хān Tengger 1982: 158-162; Šinǰiyang-giyin aman üliger 2006: 127-129]. Этот сказочный сюжет близок к сюжету «Куропатка и лиса», распространенному в рамках комментаторской тибето-монгольской литературы к буддийским дидактическим трактатам [Ёндон 2013: 61]. В финале мудрая птица спасается из пасти лисы, лишившись своего хвоста. Этим обстоятельством объясняется, почему у перепелки хвост короткий, а потому сказка приобретает этиологическое содержание.

Еще одним вариантом этой сказки является текст «Лиса и перепелка». Лиса обнаруживает птенцов перепелки. Ради спасения своих детей, птица обещает досыта накормить лису и приводит к дому одной богатой семьи. Она отвлекает, уводит домочадцев, в это время лиса досыта наедается тем, что находит в доме. В следующий раз лиса велит перепелке рассмешить ее. Перепелка прилетает к дому той же богатой семьи и садится на голову хозяину. Жена хозяина решает убить птицу, ударив плетью, но вместо перепелки попадает в голову мужа. Разгневанный хозяин гонится за глупой супругой, они удаляются далеко от дома. Лиса, наблюдавшая за всем происходящим из кустов, нахохотавшись до слез от увиденного, вновь беспрепятственно наедается вдоволь. В третий раз лиса требует, чтобы перепелка напугала ее. Та приводит ее к охотникам с собаками - лиса едва спасает свою жизнь. После пережитого страха перед смертельной опасностью лиса от злости решается съесть перепелку, но лишь отрывает ей хвост. С тех пор у перепелки хвост короткий, а у лисы - длинный [Xān Tengger 1981, № 3: 179-182]. Соответствий этому сюжету в калмыцком фольклоре нами не обнаружено.

В сказке «Лиса, ёж и лягушка» («Ünegen zara mekelei jurban») персонажи устраивают соревнование, чтобы определить, кому достанется найденное масло, а кому отправляться в ночной караул. Лягушка с помощью хитрой уловки выигрывает состязание. Лиса и еж остаются без масла и отправляются в ночной караул [Xān Tengger 1986: 191-193; Šinǰyang-giyin aman üliger 2006: 552-554].

В другой сказке «Лиса и еж» («Ünegen zarā xoyor») хитрая лиса и мудрый ёж выясняют, кто из них старше. Лиса заявляет, что мать убаюкивала ее в то время, когда земля еще была размером с очаг, небо - размером с косичку, а птица попугай - неоперившимся птенцом. В ответ мудрый еж говорит, что тогда лиса выходит ровесницей его младшего брата, после чего лиса вынуждена признать его старшинство [Šinǰiyang-giyin aman üliger 2006: 539]. Этот сказочный сюжет известен в рамках комментаторской литературы буддизма [Владимирцов 1921: 30-31; Ёндон 2013: 79]. 


\section{Монголоведение • Mongolian Studies • 2020 ๑ T. 12 • № 2}

Сюжеты некоторых сказок построены на конфликте между животными, которые делят найденную еду. Раздел выращенного урожая становится основой конфликта в сказке «Лиса, лягушка и кузнечик» («Ünegen, mekelei, carcā zurba»). Возникает спор, который по предложению лисы, должен разрешиться в беге наперегонки. Кузнечик, уцепившись за ухо лисы, оказывается первым. Лягушка, прискакавшая последней, измазала себя кровью и сказала, что ранена лошадью охотника и потеряла много сил, но не могла не предупредить лису, поэтому превозмогая страдания, добралась из последних сил, чтобы сообщить ей об опасности. Испуганная лиса убегает прочь, а лягушка и кузнечик делят собранный урожай и продолжают дружно жить дальше [Altai tayiǰ 1985: 356-358; Šinǰiyang-giyin... aman üliger 2006: 539-540]. Вариантом этого сюжета является сказка «Лягушка, лиса и паук» («Mekelei, üngen, arālǰin») [Xān Tengger 1981, № 3: 170-172; Šinǰiyang-giyin aman üliger 2006: 571]. Среди опубликованных источников соответствий этому сюжету в калмыцком фольклоре не обнаружено.

В сказке «Как лиса была ханом» («Ünegen xān suuqsa-ni») выкрашенная в синий цвет лиса представляется ханшей всех животных, рожденной по воле Хурмусты-тенгрия, но выдает себя своим воем и оказывается убитой разгневанными зверями [Betege саүān boqširyo 1981: 59-61; Šinǰiyang-giyin aman üliger 2006: 542]. Сказка схожа со сказочным сюжетом «Голубая лиса», который был широко распространен в рамках комментаторской тибето-монгольской литературы к буддийским дидактическим трактатам [Ёндон 2013: 69-70].

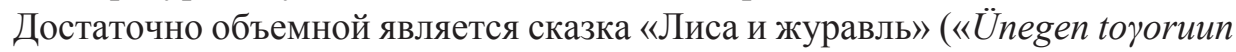
xoyor»), в которой лиса, притворившись доброй соседкой, пытается съесть птенцов журавля. Птица в отместку устраивает так, что лиса попадает в капкан [Xān Tengger 1985: 127-131; Šinǰiyang-giyin aman üliger 2006: 535-536].

В сказке «Как мышь перехитрила лису» мышка, попавшись лисе, спасается с помощью хитрой уловки («Xulyuna ünegen-yigi mekeleqsen») [Xān Tengger 1988: 60; Šinǰiyang-giyin aman üliger 2006: 555].

Старший и младший братья-мыши спорят из-за найденного кусочка масла в сказке «Семь братьев мышей» («Axa dü̈̈ dolōn хulyuna»). Старший брат обращается за разрешением спора к лисе. Лиса хитростью выманивает младшего брата и хочет его съесть. Мышонок освобождается, обманом заставив лису трижды перекинуть его через себя [Šinǰiyang-giyin aman üliger 2006: 555-556].

В сказке «Шесть волков и одна лисица, проигравшие пяти братьям» («Zuryān čono nige ünegen axa düü tabun-du šüüqdeqsen») лиса поет угрожающую песню пяти друзьям-братьям (годовалые бычок, верблюжонок, жеребенок, ягненок и козленок), которые пришли на их пир. В ответ пятеро братьев исполняют не менее угрожающую песню. Лиса и шесть волков, испугавшись, покидают пир [Šinǰiyang-giyin aman üliger 2006: 552].

Волк решает поживиться козленком и бычком в одноименной сказке «Козленок и бычок» («Išige teke bürüü buxu»). Оставив попытки поймать козленка, взобравшегося на отвесный склон, волк погнался за бычком. Застрявший в расщелине бычок пугает волка тем, что охотничьи собаки, которых он проглотил, рвутся наружу, чтобы его съесть. Испугавшийся волк убегает. В лесу ему 
встречается сначала человек, шедший в лес за хворостом, а затем лиса. Узнав причину страха волка, плутовка уговаривает волка вернуться и съесть бычка. Когда они отправляются назад, им встретился тот самый человек, который возвращался с хворостом. Человек, испугавшись волка, размахивая топором, стал кричать, что лиса обещала привести семь волков, а привела лишь одного. Испуганный волк пустился наутек и веревка, которую они повязали на шею вместе с лисой, задушила еe [Šinǰiyang-giyin aman üliger 2006: 561-563].

Лисица и лис погибают из-за собственной жадности и глупости в сказке «Две скупые лисы» («Xobdoq xoyor ünegen») [Betege caүān boqširyo 1981: 12 13; Šinǰiyang-giyin aman üliger 2006: 550-551].

Сложный контаминированный сюжет в сказке «Скупая черно-бурая лисица» («Xobdoq xaltar ünegen») включает три сюжета. В первом речь идет о конфликте слона и муравьев, которые убивают его, забравшись к нему внутрь. Во втором сюжете войско, направленное на уничтожение слона, погибает, уничтожив друг друга. В третьем сюжете появляется лиса, которая, увидев такое огромное количество трупов, приходит в восторг и погибает от случайной стрелы [Betege саүān boqširyo 1981: 62-64; Šinǰiyang-giyin aman üliger 2006: 554].

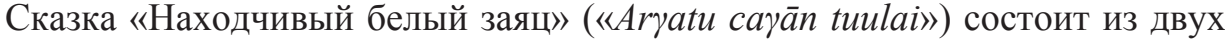
сюжетов. В первом из них заяц с помощью хитрой уловки спасает овечку, возвращавшуюся из паломничества в Тибет. Заяц заявляет барсу, что он ест свой зрачок. Барс желает попробовать свой глаз, заяц ножом выковыривает его, но дает вместо зрачка изюм. Барс решает съесть второй свой глаз, а потом овцу с ягненком. Заяц вместо них предлагает барсу говядину, приводит его на вершину скалы и разводит костер. Советует ему отодвинуться от огня, чтобы не опалить шерсть. Барс отсаживается подальше, срывается со скалы, но хватается за сук зубами. Заяц вынуждает барса крикнуть, чтобы доказать, что он славный старший брат, из-за чего барс срывается и разбивается насмерть. Во второй части заяц обманом заставляет лису притвориться хромой, чтобы увести ламу-священника, а сам овладевает его вещами и чинит беды другим животным. Злого и неблагодарного зайца люди отправляют на луну. Этим обстоятельством объясняется, почему пятно на луне похоже на зайца. Таким образом, сказка в финале обретает этиологическое наполнение [Xān tengger 1982, № 3: 163-171].

В сказке «Хвост верблюда» («Tете̄ni sü̈̈l») лиса подговаривает волка, барса и медведя напасть на верблюда. После чего устраивает так, что барс убивает медведя и волка. Пока барс расправлялся с ними, лиса прячет мясо верблюда, а хвост засовывает в расщелину скалы. Барс, дернув за хвост, срывается со скалы. Скупая лиса, грызшая хвост верблюда, лежа у входа в пещеру, куда она спрятала мясо верблюда, становится добычей орла [Betege caүān boqširyo 1981: 16-20; Šinǰiyang-giyin aman üliger 2006: 549-550].

Как видно из представленных сюжетов, лисе как персонажу сказок о животных одинаково присущи как хитрость, так и глупость. Речь лисы изобилует эпитетами и обращениями, льстящими тому, к кому она обращается. Образность и поэтичность речей лисы оформляются в рифму, поэтому в некоторых 
текстах ее речь дается в стихотворной форме. Лиса использует разные уловки, чтобы достигнуть поставленных целей. Тонко играя на чувствах других персонажей, она хитростью, лестью, обманом, угрозами, жалостью, притворным состраданием добывает себе пропитание.

\section{Сюжеты сказок, где лиса торжествует}

В сюжете «Хитрая лиса, умертвившая волка» («Xulǰin ünegen čono-yigi xorlaqsan-ni») лиса, якобы помогая волку, приводит его к капкану, установленному стариком. Попавшего в ловушку хищника старик убивает, а лиса съедает приманку, избежав попадания в капкан [Xān tengger 1991: 121-123].

На контаминации двух широко распространенных международных сюжетов «Лиса крадёт рыбу из саней» и «Волк у проруби» построена сказка «Волк и лиса» («С̌ono ünegen xoyor»). В финале сюжета волк погибает от рук людей изза примерзшего в проруби хвоста [Betege caүān boqširyo 1981: 6-8; Šinǰiyanggiyin aman üliger 2006: 536-537]. Этот сюжет хорошо известен в фольклоре многих народов.

Лиса мстит волку и отправляет его на поиски драгоценной исцеляющей пилюли в сказке «Волк, искавший исцеляющую пилюлю» («Ürēl xayiqsan čono»). Лиса выдает за пилюлю, дарующую долголетие, изюм. Подсказывает волку, где ее можно раздобыть, и советует громко петь, чтобы пилюля начала действовать. В финале сюжета волк, пробравшийся в джолум, погибает из-за того, что, опьянев, начинает громко выть и прибежавшие люди убивают его [Betege caүān boqširyo 1981: 32-35; Šinǰiyang-giyin aman üliger 2006: 537-538]. Соответствий этому сюжету в калмыцком фольклоре не обнаружено.

Лиса уговаривает верблюда отдать себя на съедение в сказке «Лиса, барс и волк» («Ünegen, bar, čono yurban»)». По подсказке лисы тигр и волк наедаются так, что не могут убежать и погибают от рук хозяина верблюда [Altai tayiji 1985: 355-356; Šinǰiyang-giyin aman üliger 2006: 538-539].

В сказке «Верблюд, лис, волк и барс» («Temē ünegen čono bars dörbü») животные становятся побратимами. Когда приходит зима, лиса убеждает волка и барса съесть верблюда. Затем с помощью хитрости и обмана убивает волка, наведя его на капкан. После того как охотник убил волка и содрал с него шкуру, лиса спрятал тушу. Затем она хитростью заставляет спрыгнуть барса с вершины горы. Так лиса, питаясь мясом своих собратьев, переживает зиму [Xān tengger 1987: 128-130].

В калмыцкой устной традиции сказка с подобным названием «Барс, волк, лиса и верблюд» («Барс, чон, арат, темән дөрвн») представляет собой контаминацию двух вышеуказанных сюжетов «Лиса, барс и волк» и «Хвост верблюда». В синьцзянской версии сказки «Лиса, барс и волк» простодушный верблюд соглашается на съедение, потому что лиса обещает ему сотворить еще одного верблюда у нее в желудке. В калмыцкой версии лиса предлагает съесть верблюда, так как его мяса хватит на всех, а весной он может переродиться в семерых верблюжат. В калмыцкой сказке далее идет разработка сюжета, схожего со сказкой «Хвост верблюда», но без финального эпизода с хвостом верблюда [Хальмг туульс 1961: 72-73].

Следующий сюжет из данной группы повествует о том, как лис с помощью хитрости делает своей ездовой птицей Хан Гаруди (сказка «Лис-перерожде- 


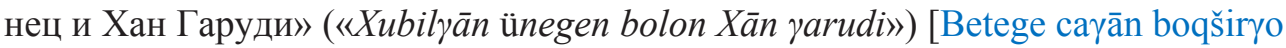
1981: 38-39; Šinǰiyang-giyin aman üliger 2006: 542-543]. Этот сказочный сюжет близок к рассказу «Вишну и Гаруда», широко известному в рамках комментаторской тибето-монгольской литературы к буддийским дидактическим трактатам [Ёндон 2013: 124-125]. Соответствий этому сюжету в калмыцком фольклоре не обнаружено.

Сюжет о том, как лиса хитростью заставляет льва самому нести тяжелую добычу называется «Лев и лиса» («Arslang ünegen xoyor») [Betege caүān boqširyo 1981: 14-15; Šinǰiyang-giyin aman üliger 2006: 550]. Этот сюжет также известен в рамках комментаторской тибето-монгольской литературы к буддийским дидактическим трактатам под названием «Лиса и лев» [Ёндон 2013: 144-145].

«Сказка о серой овечке» («Boro xoyini üliger») представляет собой сложный контаминированный текст, состоящий из двух сюжетов. В первом находчивый заяц с помощью хитрой уловки спасает овечку, возвращавшуюся из паломничества в Тибет, от тигра, волка и лисы. Во втором лиса, спасая собственную жизнь, хитростью убивает тигра и волка, отправив их ловить рыбу на льду реки [Xān Tengger 1990. № 1: 37-40; Šinǰiyang-giyin aman üliger 2006: 560-561].

На широко распространенном в мировом фольклоре сюжете построена сказка «Обезьяна, голубь и лиса» («Sarmečin kögülÿirgene ba ünegen»). Лиса хитростью выманивает деньги у обезьяны, которая захотела увеличить их количество, зарыв под корнем золотого тополя [Xān tengger 1981. № 3: 175-178; Šinǰiyang-giyin aman üliger 2006: 572-573].

Заставив глупого медведя разрывать ямку сурка, хитрая лиса подманивает охотника в сказке «Лиса и медведь» («Ünegen ba ötöge»). Охотник убивает медведя и, сняв шкуру, бросает тушу. Лиса наедается мясом медведя [Ха̄n tengger 1981. № 3: 173-174; Šinǰiyang-giyin aman üliger 2006: 572].

В сказке «Как мышь проиграл лису» («Xuluүuna ünegen-dü ideqdeqsen-ni») лис с помощью угроз мышам и лести, расточаемой царю зверей, съедает всю мышиную семью [Хān tengger 1982, № 3; 174-177].

Сюжет «Лиса и ворона», имеющий широкое распространение в устной традиции многих народов, представлен и в синьцзянской. Вынудив льстивыми речами ворону каркнуть, лиса лишает ее добычи («Ünegen kerē xoyor») [Šinǰiyang-giyin aman üliger 2006: 99-100].

\section{Выводы}

В большинстве сказочных сюжетов обман лисы приводит к гибели животных. Реже описаны более мягкие последствия ее проделок: отнимает кусок мяса, серебряные монеты, делает ездовой птицей, заставляет нести тяжелую добычу. В рассмотренных нами текстах сказок ойратов Синьцзяна лиса неизменно предстает в роли трикстера, обманывая не только животных, но и людей. Однако, как видно из представленного материала, лиса далеко не всегда оказывается победителем, но достаточно часто становится жертвой других персонажей.

\section{Литература}

Владимирцов 1921 - Владимирцов Б. Я. Монгольский сборник рассказов из Pañcatantra // Сборник Музея антропологии и этнографии при Российской Академии наук. Т. 5. Пг.: Акад. 12-я гос. тип., 1921. Вып. 2. С. 401-552. На русск. и монг. яз. 
Ёндон 2013 - Ёндон Д. Сказочные сюжеты в памятниках тибетской и монгольской литератур. 2-е изд. Уланбаатар: АНМ ИЯЛ, 2013. 201 с.

Басангова 2010 - Басангова Т. Г. Мифы, легенды, предания // Калмыки. М.: Наука, 2010. C. 304-312.

Басангова 2019 - Басангова Т. Г. Животные в калмыцком фольклоре. На рус. и калм. яз. Элиста: КалмГУ, 2019. 192 с.

Николаева 2010 - Николаева Н. Н. Лиса в эпическом фольклоре бурят // Вестник Бурятского государственного университета. 2010. № 10. С. 277-283.

Пропп 2000 - Пропn В. Я. Русская сказка (Собрание трудов В. Я. Проппа) / науч. ред., коммент. Ю. С. Рассказова. М.: Лабиринт, 2000. 416 с.

Содномпилова, Нанзатов 2016 - Содномпилова М.М., Нанзатов Б.З. Зооморфный код в контексте этногенетических связей: лиса в традиционных представлениях монгольских народов // Известия Иркутского государственного университета. Сер.: Геоархеология. Этнология. Антропология. 2016. Т. 15. С. 48-63.

Шараева 2011 - Шараева Т. И. Обряды жизненного цикла калмыков (ХІХ в. - нач. ХХ в.). Элиста: НПП «Джангар», 2011. 223 с.

Хальмг туульс. I боть. Барт белдснь Б. Саңһжин, Л. Саңһан (=Калмыцкие сказки. Книга 1. Составители Б. Сангаджиев, Л. Сангаев). Элст: Хальмг дегтр һарһач (Элиста: Калм. кн. изд-во), 1961. 220 х.

Ardag küreng moritai Altai tayiji (=Алтай-тайша на диком Рыжко). Huhhoto: Öbör Mongyol-yin soyoliyin keblel-yin xorō (Хух-Хото: Изд-во «Культура» Внутренней Монголии), 1985. $386 \mathrm{~h}$.

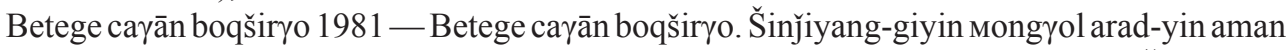
zokōl (=Белозобый воробей. Фольклор монголов Синьцзяна). Urumči: Šinǰiyanggiyin arad-yin keblel-yin xorō (Урумчи: Народное издательство Синьцзяна), 1981. $100 \mathrm{~h}$.

Damrindjab 2017 - Damrindjab Ba. Collection and Publication of Oirat Folk Tales of Xinjiang: a Brief Historical Review // Вестник Калмыцкого института гуманитарных исследований. РАН. 2017. № 6. С. 139-149.

Šinǰiyang-giyin mongyol aradiyin aman üliger 2006 - Dumdadu ulusiyin Šinǰiyang-giyin мongyol aradiyin aman üliger-yin emkidkel (=Собрание сказок монголов Синьцзяна КНР). Ürümči: Šinǰiyang-giyin aradiyin keblel-yin xorō (Урумчи: Народное издательство Синьцзяна), 2006. $866 \mathrm{~h}$.

Xān Tengger — Xān Tengger. Ürümči: Šinǰiyang-giyin aradiyin keblel-yin xorō (=Хан Тенгер. Урумчи: Народное издательство Синьцзяна). 1981-1991 (№ 1-44), 1993 (№ 45-50), 1998 (№ 51).

\section{References}

Altai Tayiji Riding a Wild Red Horse with a White-Starred Forehead. Hohhot: Inner Mongolia Culture Publ., 1985. 386 p. (In Mong.)

Basangova T. G. Animals in Kalmyk Folklore. Elista: Kalmyk State University, 2019. 192 p. (In Kalm. and Russ.)

Basangova T. G. Myths, legends, stories. In: Bakaeva E. P., Zhukovskaya N. L. (eds.) The Kalmyks. Moscow: Nauka, 2010. Pp. 304-312. (In Russ.)

Damrindjab Ba. Collection and publication of Oirat folk tales of Xinjiang: a brief historical review. Bulletin of the Kalmyk Institute for Humanities of the RAS (Oriental Studies). 2017. No. 6. Pp. 139-149. (In Russ.)

Endon D. Monuments of Tibetan and Mongolian Literature: Fairy-Tale Plots. $2^{\text {nd }}$ ed. Ulaanbaatar: Mongolian Academy of Sciences, 2013. 201 p. (In Mong.)

Khan Tenger (journal). Urumqi: Xinjiang People's Publ, 1981-1991 (no. 1-44), 1993 (no. 45-50), 1998 (no. 51). (In Mong.) 
Nikolaeva N. N. Fox in Buryat epic folklore. Buryat State University Bulletin. 2010. No. 10. Pp. 277-283. (In Russ.)

Propp V. Ya. Russian Fairy Tale: Collected Works of V. Ya. Propp. Yu. S. Rasskazov (ed., comment.). Moscow: Labirint, 2000. 416 p. (In Russ.)

Sangadzhiev B., Sangaev L. (comps.) Kalmyk Tales. Vol. 1. Elista: Kalmyk Book Publ., 1961. 220 p. (In Kalm.)

Sharaeva T. I. Kalmyk Life-Cycle Rituals: $19^{\text {th }}-$ Early $20^{\text {th }}$ Centuries. Elista: Dzhangar, 2011. 223 p. (In Russ.)

Sodnompilova M. M., Nanzatov B. Z. Zoomorphic code in ethnogenetic context: fox in traditional beliefs of Mongolian peoples. Bulletin of the Irkutsk State University. Geoarchaeology, Ethnology, and Anthropology Series. 2016. Vol. 15. Pp. 48-63. (In Russ.)

The White-Chested Sparrow: Folklore of Xinjiang Mongols. Urumqi: Xinjiang People's Publ., 1981. 100 p. (In Mong.)

Vladimirtsov B. Ya. Collected Mongolian-language stories from the Pañcatantra. In: Museum of Anthropology and Ethnography, Russian Academy of Sciences: Collected Works. Vol. 5. Petrograd: State Academic Publ. House no. 12, 1921. Pp. 401-552. (In Russ. and Mong.)

Xinjiang Mongols, PRC: Collected Tales. Urumqi: Xinjiang People's Publ., 2006. 866 p. (In Mong.) 